\title{
New OTA-C Current-Mode Second-order and Fourth-Order Band-Pass Filters
}

\author{
Dattaguru V. Kamath \\ Professor, Dept of E\&C Engg., Manipal Institute of Technology, Manipal University, Manipal, India
}

\begin{abstract}
In this paper, a general two-admittance current-mode circuit structure using Dual-Output OTA (DO-OTA) is explored to derive new second-order and fourth-order band-pass filters. The proposed second-order band-pass filtercircuits offer advantageous features like ease of design, good sensitivity and orthogonal tunability of pole-Q. The proposed fourth-order band-pass filtercircuit is attractive as it requires less number of OTAs and capacitors.PSPICE simulation results are given for the proposed circuits.
\end{abstract}

Keywords: Continuous-time (CT) filters, Current-mode circuits,SO-OTA,DO-OTA, OTA-C filters.

\section{INTRODUCTION}

Recently, the OTA-C current-mode (CM) continuous-time (CT) filterdesign approach [1]-[13] has received more attention. The design of current-mode OTA-C filters using Dual Output OTAs (DO-OTA) [2]-[8], TO-OTA[9], [10] and Multiple Output OTAs (MO-OTA) [5], [11]-[13] have been described. The different circuit configurations for realization of current-mode biquads using OTA have been describedi.e., a single DO-OTA and five admittance model [3], two-integrator loop structure [4]-[6]etc. The DO-OTA based general two-admittance circuit configuration with two/ one input current(s) has been discussed extensively in the literature [6], [8], [12], [14]. The realization of third-order OTA-C filters also has been researched in the literature [14]-[16].

The realization of OTA-C current-mode second-order band-pass filters are discussed [4], [5], [8], [12]. The thirdorder OTA-C current-mode band-pass filters with unsymmetrical amplitude response have been investigated [14]-[16]. The design of fourth-order band-pass Active-RC filters have been reported [17]-[19].

In this paper, the DO-OTA based general current-mode two-admittance circuit structure proposed in [6], [8], [12], [14] is presented in Section II. In Section III, the proposed general basic topology is used to explore second-order and fourth-order band-pass filters by considering proper admittances in place of $Y_{n}$ and $Y_{p}$. In Section IV, the proposed fourth-order OTA-C current-mode band-pass filter is compared with the cascade band-pass filter arrangement using two identical band-pass biquads. PSPICE simulation results are presented in Section V. The concluding remarks are given in Section VI.

\section{DO-OTA BASED TWO-ADMITTANCE CIRCUIT CONFIGURATION}

The circuit symbol of single output OTA (SO-OTA) and dual output OTA (DO-OTA) used in this work are shown in Fig. 1(a) and (b) respectively. The two current outputs of DO-OTA are given by

$$
\mathrm{I}_{\mathrm{o} 1}+=\mathrm{I}_{\mathrm{o} 2}+=\mathrm{g}_{\mathrm{m}}\left(\mathrm{V}_{\mathrm{i}}^{+}-\mathrm{V}_{\mathrm{i}}^{-}\right)
$$

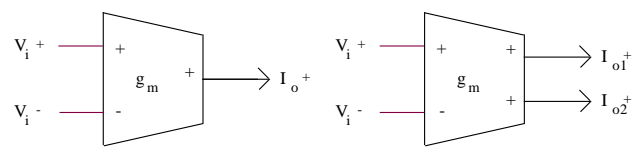

(a)

(b)

Fig.1 Circuit symbol of (a) SO-OTA (b) DO-OTA

Here, $\mathrm{I}^{+}{ }^{+}, \quad \mathrm{I}_{\mathrm{o} 2}^{-}$are the two output source currents, $\mathrm{V}_{\mathrm{i}}^{+}$and $\mathrm{V}_{\mathrm{i}}^{-}$denote non-inverting and inverting input voltages of the DO-OTA respectively.

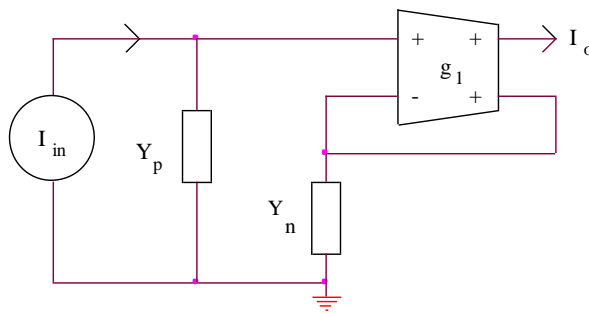

Fig.2 DO-OTA based general current-mode two-admittance circuit configuration with single input current

The DO-OTA based two-admittance general current-mode configuration with two input currents has been discussed in [7].The circuit configuration with single input current for realizing OTA-C third-order band-pass filters is shown in Fig. 2. The generalized current-input current-output (CICO) transfer function for this circuit can be shown to be

$$
\frac{I_{o}}{I_{\text {in }}}=\frac{g_{1} Y_{n}}{Y_{p}\left(g_{1}+Y_{n}\right)}(2)
$$

\section{REALIZATION OF CURRENT-MODE OTA-C SECOND-ORDERAND FOURTH-ORDER BAND- PASS FILTERS}

A. Current-mode OTA-C second-order band-pass filter BP2

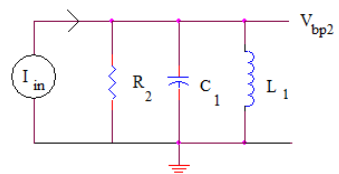

(a) 


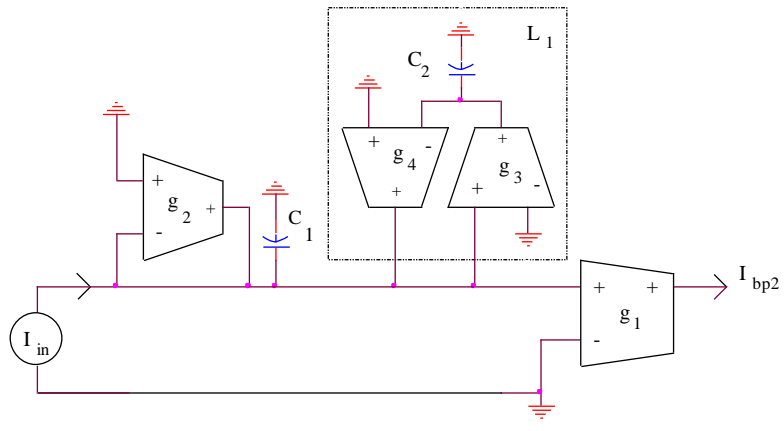

(b)

Fig. 3 (a) Second-order passive RLCtransimpedance band-pass filter circuit reported in [2] (b) Current-mode second-order band-pass filter BP2 derived from the configuration of Fig. 2

The transfer function of passive RLC transimpedance band-pass biquadin Fig. 3(a) reported in [ ] is shown to be

$$
\frac{V_{b p 2}}{I_{\text {in }}}==\frac{s\left(\frac{1}{C_{1}}\right)}{s^{2}+s\left(\frac{1}{R_{2} C_{1}}\right)+\frac{1}{L_{1} C_{1}}}(3 a)
$$

A current-modesecond-order band-pass filter circuit in Fig. 3(b) is obtained by using the basic structure of Fig. 2 by replacing the admittance $\mathrm{Y}_{\mathrm{p}}$ withaparallel RLC resonator (consisting of grounded inductor $\mathrm{L}_{1}$, grounded OTA simulated resistor $1 / g_{2}$ and grounded capacitor $C_{1}$ ) and $Y_{n}$ $=\infty$ (grounding negative input of OTA $\mathrm{g}_{1}$ ). Here the inductance $L_{1}$ of value $\mathrm{C}_{2} / \mathrm{g}_{3} \mathrm{~g}_{4}$ is realized by OTAs $\mathrm{g}_{3}$ and $\mathrm{g}_{4}$ and capacitor $\mathrm{C}_{2}$. The transfer function of OTA-C currentmode band-pass biquadBP2 in Fig. 3(b) is given by

$$
\frac{I_{b p 2}}{I_{\text {in }}}==\frac{s\left(\frac{g_{1}}{c_{1}}\right)}{s^{2}+s\left(\frac{g_{2}}{C_{1}}\right)+\frac{g_{3} g_{4}}{C_{1} C_{2}}}
$$

The expressions for pole-frequency and pole-Q are shown to be

$$
\omega_{o}=\sqrt{\frac{g_{3} g_{4}}{C_{1} C_{2}}} ; \quad Q_{o}=\frac{g_{3,4}}{g_{2}} \sqrt{\frac{C_{1}}{C_{2}}}
$$

Note that current-mode band-pass OTA-C biquad BP2 in Fig. 3(b) is an extension of passive transimpedancebiquadusing an additional OTA $\mathrm{g}_{1}$ as a voltage-to-current converter.

\section{B. Current-mode OTA-C second-order band-pass filter} $\mathrm{BP} 2 *$

The current-mode second-order band-pass filter circuit shown in Fig. 4 can be realized from the basic structure of Fig. 2 by replacing the admittance $Y_{p}$ with grounded resistor $1 / g_{2}$ and $Y_{n}$ with $C_{3}$ in series with grounded inductor $\mathrm{L}_{2}$. Here the grounded inductance $\mathrm{L}_{2}$ of value $\mathrm{C}_{4} / \mathrm{g}_{5} \mathrm{~g}_{6}$ is realized by OTAs $\mathrm{g}_{5}$ and $\mathrm{g}_{6}$ and capacitor $\mathrm{C}_{4}$.

The current-mode second-order band-pass transfer function realized by the $\mathrm{BP} 2 *$ filter circuit in Fig. 4 are given by

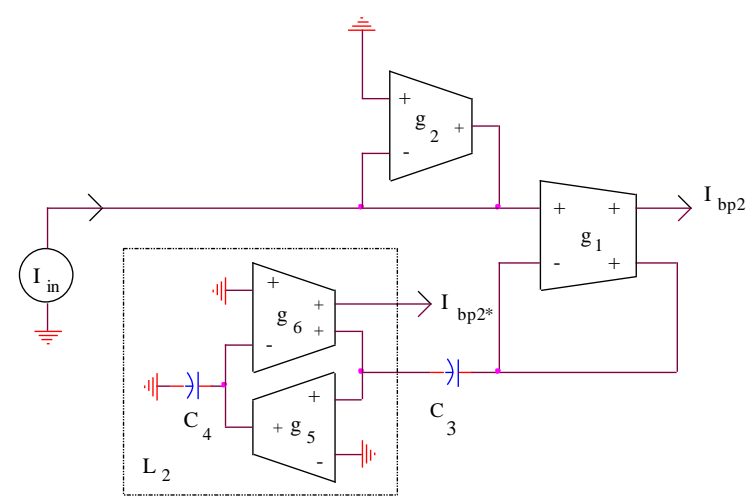

Fig. 4Current-mode second-order band-pass filter BP2/ BP2* derived from the configuration of Fig. 2

$$
\frac{\mathrm{I}_{\mathrm{bp} 2}}{\mathrm{I}_{\mathrm{in}}}=-\frac{\mathrm{I}_{\mathrm{bp} 2 *}}{\mathrm{I}_{\mathrm{in}}}=\left(\frac{g_{1}}{g_{2}}\right) \frac{s\left(\frac{g_{5} g_{6}}{g_{1} C_{4}}\right)}{s^{2}+s \frac{g_{5} g_{6}}{g_{1} C_{4}}+\frac{g_{5} g_{6}}{C_{3} C_{4}}}(4 \mathrm{a})
$$

The expressions for pole-frequency and pole-Q are shown to be

$$
\omega_{o}=\sqrt{\frac{g_{5} g_{6}}{C_{3} C_{4}}} ; \quad Q_{o}=g_{1} \sqrt{\frac{C_{4}}{g_{5} g_{6} C_{3}}}
$$

\section{C.Current-mode OTA-C fourth-order band-pass filter $\mathrm{BP} 4 / \mathrm{BP} 4 *$}

In this section we show that the general basic topology of Fig. 2 can be used to realize fourth-order band-pass filter circuit.

A current-modefourth-order band-pass filter circuit is obtained by using the basic structure of Fig. 2 by replacing the admittance $Y_{\mathrm{p}}$ withaparallel $\mathrm{RLC}$ resonator (consisting of grounded inductor $\mathrm{L}_{1}$, grounded OTA simulated resistor $1 / \mathrm{g}_{2}$ and grounded capacitor $\mathrm{C}_{1}$ ) and $\mathrm{Y}_{\mathrm{n}}$ with a series $\mathrm{LC}$ section ( acapacitor $\mathrm{C}_{3}$ in series with grounded inductor $\mathrm{L}_{2}$ ). Note that the inductance $\mathrm{L}_{1}$ of value $\mathrm{C}_{2} / \mathrm{g}_{3} \mathrm{~g}_{4}$ is realized by OTAs $\mathrm{g}_{3}$ and $\mathrm{g}_{4}$ and capacitor $\mathrm{C}_{2}$ and theinductance $\mathrm{L}_{2}$ of value $\mathrm{C}_{4} / \mathrm{g}_{5} \mathrm{~g}_{6}$ is realized by OTAs $\mathrm{g}_{5}$ and $\mathrm{g}_{6}$ and capacitor $\mathrm{C}_{4}$. Theresulting circuit is presented in Fig.5.

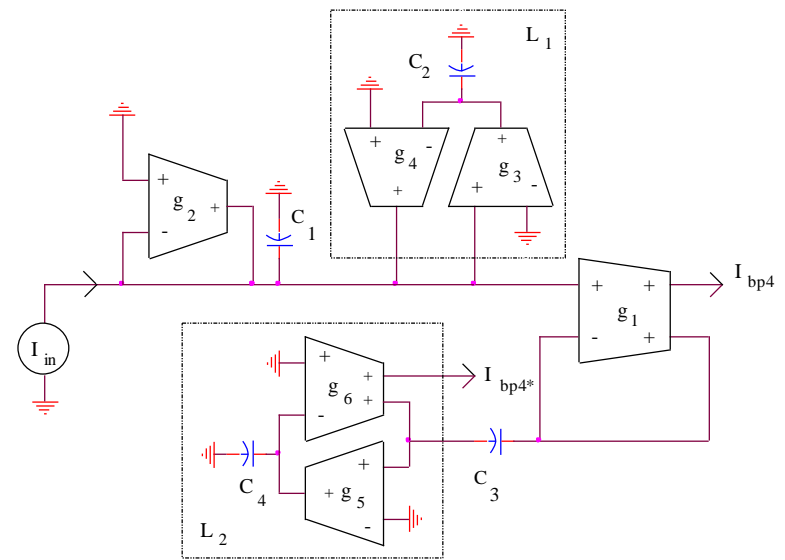

Fig.5 Current-mode DO-OTA based fourth-order band-pass filter BP4/ BP4* derived from the configuration of Fig. 2 
The current-mode fourth-order band-pass transfer function for the circuit of Fig. 5is shown to be

$$
\mathrm{T}_{\mathrm{bp} 4}(\mathrm{~s})=\frac{\mathrm{I}_{\mathrm{bp} 4}}{\mathrm{I}_{\mathrm{in}}}=-\frac{\mathrm{I}_{\mathrm{bp} 4} *}{\mathrm{I}_{\mathrm{in}}}=\frac{\mathrm{s}^{2} \beta_{2}}{\mathrm{~s}^{4}+\mathrm{s}^{3} \alpha_{3}+\mathrm{s}^{2} \alpha_{2}+\mathrm{s} \alpha_{1}+\alpha_{0}}(3 \mathrm{a})
$$

where

$$
\begin{gathered}
\beta_{2}=\frac{g_{5} g_{6}}{C_{1} C_{4}} \\
\alpha_{3}=\frac{g_{2}}{C_{1}}+\frac{g_{5} g_{6}}{g_{1} C_{4}} \\
\alpha_{2}=\frac{g_{3} g_{4}}{C_{1} C_{2}}+\frac{g_{5} g_{6}}{C_{3} C_{4}}+\frac{g_{2} g_{5} g_{6}}{g_{1} C_{1} C_{4}} \\
\alpha_{1}=\frac{g_{2} g_{5} g_{6}}{C_{1} C_{3} C_{4}}+\frac{g_{3} g_{4} g_{5} g_{6}}{g_{1} C_{1} C_{2} C_{4}} \\
\alpha_{0}=\frac{g_{3} g_{4} g_{5} g_{6}}{C_{1} C_{2} C_{3} C_{4}}
\end{gathered}
$$

But, the routine analysis shows an interesting observation that the fourth-order transfer function can be expressed as a cascade of two band-pass biquad sections having independent tunability of pole-Q and pole-frequency.

$$
\mathrm{T}_{\mathrm{bp} 4}(\mathrm{~s})=\mathrm{K}_{\mathrm{bp} 4} * \mathrm{~T}_{\mathrm{bp} 21}(\mathrm{~s}) * \mathrm{~T}_{\mathrm{bp} 22}(\mathrm{~s})
$$

where

$$
\begin{gathered}
\mathrm{K}_{\mathrm{bp} 4}=\mathrm{g}_{1} / \mathrm{g}_{2} \\
\mathrm{~T}_{\mathrm{bp} 21}(\mathrm{~s})=\frac{\mathrm{s}\left(\frac{\mathrm{g}_{2}}{\mathrm{C}_{1}}\right)}{\mathrm{s}^{2}+\mathrm{s} \frac{\mathrm{g}_{2}}{\mathrm{C}_{1}}+\frac{\mathrm{g}_{3} \mathrm{~g}_{4}}{\mathrm{C}_{1} \mathrm{C}_{2}}} \\
\mathrm{~T}_{\mathrm{bp} 22}(\mathrm{~s})=\frac{\mathrm{s}\left(\frac{\mathrm{g}_{5} \mathrm{~g}_{6}}{\mathrm{~g}_{1} \mathrm{C}_{4}}\right)}{\mathrm{s}^{2}+\mathrm{s} \frac{\mathrm{g}_{5} \mathrm{~g}_{6}}{\mathrm{~g}_{1} \mathrm{C}_{4}}+\frac{\mathrm{g}_{5} \mathrm{~g}_{6}}{\mathrm{C}_{3} \mathrm{C}_{4}}}
\end{gathered}
$$

The pole frequency and quality factor of the two inherent band-pass biquad transfer functions (i.e., $\mathrm{T}_{\mathrm{bp} 21}$ and $\mathrm{T}_{\mathrm{bp} 22}$ ) and their sensitivity valuesare shown to be

$$
\begin{aligned}
& \mathrm{f}_{\mathrm{o} 1}=\frac{1}{2 \pi} \sqrt{\frac{\mathrm{g}_{3} \mathrm{~g}_{4}}{\mathrm{C}_{1} \mathrm{C}_{2}}} ; \quad \mathrm{Q}_{\mathrm{o} 1}=\frac{1}{\mathrm{~g}_{2}} \sqrt{\frac{\mathrm{g}_{3} \mathrm{~g}_{4} \mathrm{C}_{1}}{\mathrm{C}_{2}}} \\
& f_{o 2}=\frac{1}{2 \pi} \sqrt{\frac{g_{5} g_{6}}{C_{3} C_{4}}} ; \quad Q_{o 2}=g_{1} \sqrt{\frac{C_{4}}{g_{5} g_{6} C_{3}}}(3 c) \\
& S_{g_{3}}^{f_{o 1}}=S_{g_{4}}^{f_{o 1}}=-S_{C_{1}}^{f_{o 1}}=-S_{C_{2}}^{f_{o 1}}=0.5 \\
& S_{g_{5}}^{f_{o 2}}=S_{g_{6}}^{f_{o 2}}=-S_{C_{3}}^{f_{o 2}}=-S_{C_{4}}^{f_{o 2}}=0.5 \\
& \mathrm{~S}_{\mathrm{g}_{3}}^{\mathrm{Q}_{01}}=\mathrm{S}_{\mathrm{g}_{4}}^{\mathrm{Q}_{01}}=\mathrm{S}_{\mathrm{C}_{1}}^{\mathrm{Q}_{01}}=-\mathrm{S}_{\mathrm{C}_{2}}^{\mathrm{Q}_{01}}=0.5 \\
& \mathrm{~S}_{\mathrm{C}_{4}}^{\mathrm{Q}_{\mathrm{o} 2}}=-\mathrm{S}_{\mathrm{g}_{5}}^{\mathrm{Q}_{\mathrm{o} 2}}=-\mathrm{S}_{\mathrm{g}_{6}}^{\mathrm{Q}_{\mathrm{o} 2}}=-\mathrm{S}_{\mathrm{C}_{3}}^{\mathrm{Q}_{\mathrm{o} 2}}=0.5
\end{aligned}
$$

$$
\mathrm{S}_{\mathrm{g}_{1}}^{\mathrm{Q}_{\mathrm{o} 2}}=-\mathrm{S}_{\mathrm{g}_{2}}^{\mathrm{Q}_{\mathrm{o} 1}}=1
$$

\section{SUMMARY OF PROPOSED FOURTH- ORDERCURRENT-MODEOTA-C BAND-PASS FILTERS}

Using the proposed DO-OTA based circuit configuration of Fig. 2, $4^{\text {th }}$ order band-pass filter circuit is shown to be realizable. In Table 1 the proposed $4^{\text {th }}$ order current-mode band-pass filter of Fig. 5 is compared with $4^{\text {th }}$ order cascade band-pass filter realized with two biquad sections of Fig. 3(b) and Fig. 4 in this paper. The proposed $4^{\text {th }}$ order band-pass filter BP4/ BP4* of Fig. 5 require six OTAs, one extra output, three grounded and one floating capacitors. The $4^{\text {th }}$ order cascade band-pass filter realized with two biquad sections of Fig. 3(b) in this paper require eight OTAsandfour grounded capacitors. The $4^{\text {th }}$ order cascade band-pass filter realized using two biquad sections of Fig. 4 in this paper require eight OTAs, one extra output, two grounded and two floating capacitors. The filter circuits are found to be attractive due to their features like ease of design, programmability, good sensitivity and independent pole-Qtunability.

Table 1 Comparative summary of various current-mode fourth-order band-pass filter circuits

\begin{tabular}{|l|l|l|l|}
\hline Author/ Reference & $\begin{array}{l}\text { No. } \\
\text { of } \\
\text { OTAs } \\
\text { OTA }\end{array}$ & $\begin{array}{l}\text { No. of } \\
\text { outputs }\end{array}$ & $\begin{array}{l}\text { No. of } \\
\text { capacitors } \\
\text { (grounded/ } \\
\text { floating) }\end{array}$ \\
\hline $\begin{array}{l}\text { Fourth-order cascade band- } \\
\text { pass filter realized with two } \\
\text { biquad sections of Fig. } \\
\text { 3(b)in this paper }\end{array}$ & 8 & 0 & 4 grounded \\
\hline $\begin{array}{l}\text { Fourth-order cascade band- } \\
\text { pass filter realized with two } \\
\text { biquad sections of Fig. 4 in } \\
\text { this paper }\end{array}$ & 8 & 2 & $\begin{array}{l}2 \text { grounded } \\
\text { floating }\end{array}$ \\
\hline $\begin{array}{l}\text { Fourth-order band-passBP4/ } \\
\text { BP4* of Fig. 5 in this paper }\end{array}$ & 6 & 1 & $\begin{array}{l}3 \text { grounded } \\
\text { floating }\end{array}$ \\
\hline
\end{tabular}

\section{V.SIMULATION RESULTS}

The proposed current-mode second-order and fourth-order band-pass filter circuits in Fig. 3(b), Fig. 4 andFig. 5 have been simulated using PSPICE simulator using Level 3 $0.5 \mu \mathrm{m}$ MOSIS model parameters and device dimensions $(\mathrm{W}=4 \mu \mathrm{m}$ and $\mathrm{L}=2 \mu \mathrm{m})$ and supply voltages $\mathrm{V}_{\mathrm{dd}}=$ $+2 \mathrm{~V}, \mathrm{~V}_{\mathrm{ss}}=-2 \mathrm{~V} .[6]$.

The proposed current-mode filter circuits were also simulated usingbehavioral voltage controlled current source (VCCS) model of OTA(i.e., ideal transconductor with infinite $R_{o}$ and zero $C_{o}$ ) to obtain the ideal characteristics. The schematic circuit ofDO-OTA used in our simulation is presented in Fig. 6. 


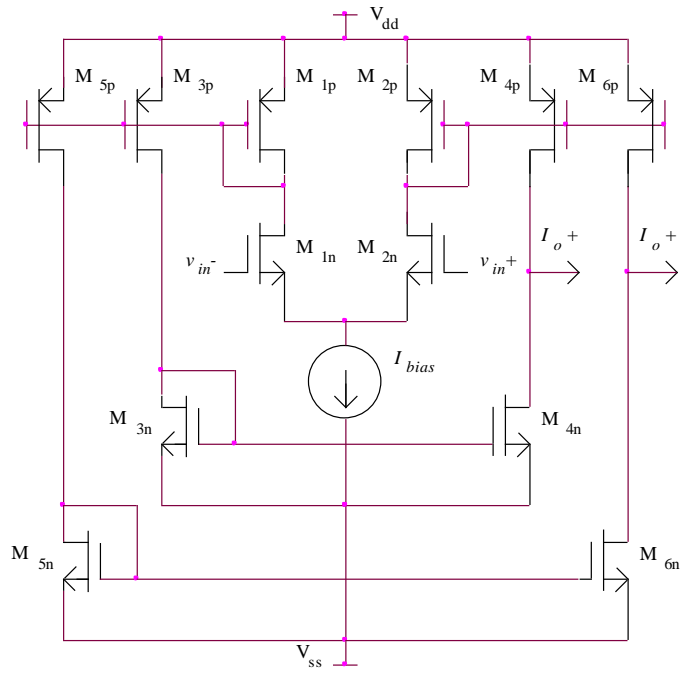

Fig.6Schematic circuit of CMOS DO-OTA
The fourth-order band-pass filter BP4of Fig. 5 have been simulated using $g_{1}=g_{2}=g_{3}=g_{4}=g_{5}=g_{6}=$ $53.9 \mu \mathrm{S}\left(I_{\text {bias } 1,2,3,4,5,6}=10 \mu \mathrm{A}\right), C_{2}=C_{3}=15 \mathrm{pF}, C_{1}=$ $C_{4}=30$ pFdesignedfor a centre frequency of $404.39 \mathrm{kHz}$ corresponding to pole- $Q Q_{o 1}=Q_{o 2}=1.414$ and the resulting amplitude responses are shown in Fig. 9.

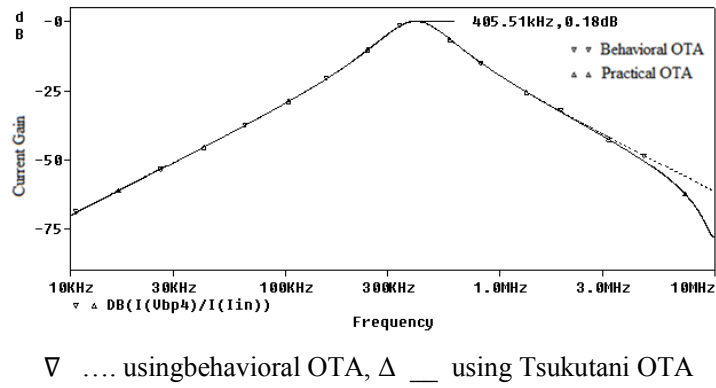

Fig. 9 Amplitude response of current-mode fourth-order band-pass filter of Fig. 5

The DO-OTA based second-order band-pass filter of Fig. From the simulatedamplitude responses, it isevident that 3(b) has been simulated using the centre frequency and gain roll-off values are found to $\mathrm{g}_{1}=\mathrm{g}_{2}=53.9 \mu \mathrm{S} \quad\left(\mathrm{I}_{\text {bias } 1,2}=10 \mu \mathrm{A}\right), \mathrm{g}_{3}=\mathrm{g}_{4}=$ $206 \mu \mathrm{S}\left(\mathrm{I}_{\text {bias } 3,4}=200 \mu \mathrm{A}\right), \mathrm{C}_{1}=\mathrm{C}_{2} 32.79 \mathrm{pF}$ designed for a center frequency of $1 \mathrm{MHz}$, pole-Q of $\mathrm{Q}_{0}=3.82$, center frequency gain of $0 \mathrm{~dB}$ and the resulting amplitude response is shown in Fig. 7.

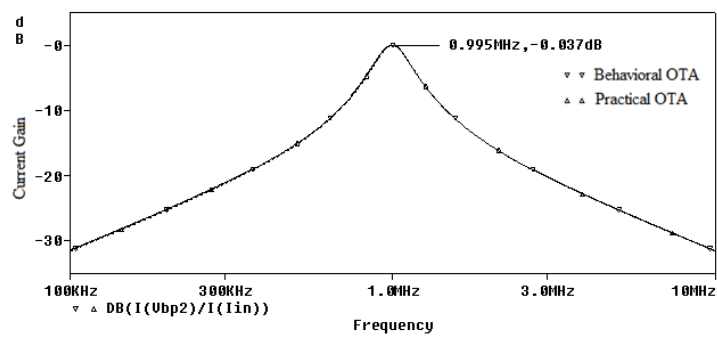

$\nabla$... usingbehavioral OTA, $\Delta_{\ldots}$ using Tsukutani OTA

Fig. 7 Amplitude response of current-mode second-order band-pass filter of Fig. 3(b)

The band-pass biquad filter of Fig. 4 have been simulated using $\quad g_{1}=114 \mu \mathrm{S}\left(I_{\text {bias } 1}=50 \mu \mathrm{A}\right), g_{2}=g_{5}=g_{6}=$ $53.9 \mu \mathrm{S}\left(I_{\text {bias } 2}=I_{\text {bias } 5}=I_{\text {bias } 6}=10 \mu \mathrm{A}\right), C_{3}=C_{4}=$ $8.58 \mathrm{pFdesignedfor} \mathrm{a} \mathrm{pole} \mathrm{frequency} \mathrm{of} 1 \mathrm{MHz}$ corresponding to pole- $Q Q_{o}=2.12$, center frequency gain of $6.506 \mathrm{~dB}$ and the resulting amplitude responses are shown in Fig. 8.

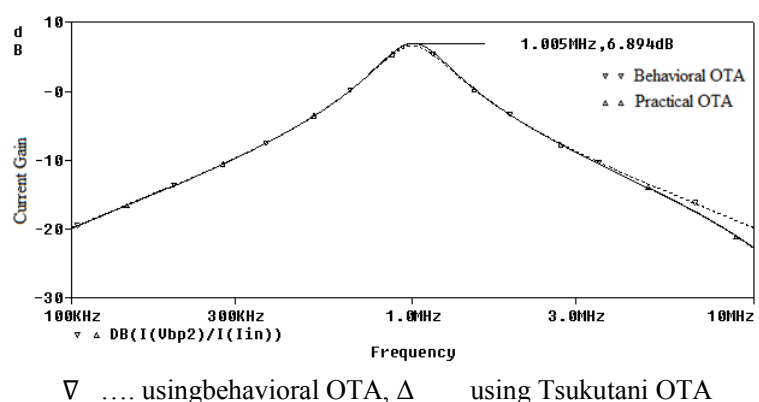

Fig. 8 Amplitude response of current-mode second-order band-pass filter of Fig. 4 be in good agreement with theory.

\section{CONCLUSION}

In this paper, a DO-OTA based general current-input current-output (CICO) two-admittance circuit configuration is used to realize second-order and fourthorder band-pass filter circuits. The proposed current-mode band-pass biquadsexhibit low sensitivity to component tolerances and provide independent tuning of polefrequency and pole-Q.The proposed fourth-order currentmode band-pass filtercircuitrequires less number of OTAsand capacitors when compared withcascade bandpass filter realized using two biquad sections. The simulation results obtained are in good agreement with

\section{REFERENCES}

[1] R. L. Geiger and E. Sanchez-Sinencio, "Active filter design using operational transconductance amplifiers: a tutorial," IEEE Circuit and Devices Magazine, vol. 1, pp. 20-32, 1985.

[2] T. Deliyannis, Y. Sun, and J. K. Fidler, Continuous-Time Active Filter Design, CRC Press, Florida, U.S.A, 1999.

[3] B. M. Al-Hashimi, "Current mode filter structure based on dual output transconductance amplifiers," Electronics Letters, vol. 32, pp. 25-26, 1996.

[4] Y. Sun, and J. K. Fidler, "Structure Generation of Current-mode Two-Integrator Loop Dual Output-OTA Grounded Capacitor Filters," IEEE Trans. Circuits and Syst. II- Analog and Digital Signal Processing, vol. 43, pp. 659-663, 1996.

[5] T. Tsukutani, Y. Sumi, and Y. Fukui, "Electronically tunable current-mode OTA-C biquad using two-integrator loop structure," Frequenz, vol. 60, pp. 53-56, 2006.

[6] Dattaguru V. Kamat, P.V. Ananda Mohan and K. GopalakrishnaPrabhu, "Novel First-order and Second-Order Current-mode filters using dual-output OTAs and Grounded Capacitors," IEEE Asia Pacific Region 10 (TENCON) Conferenceheld at Hyderabad, India,IEEExplorer, pp. 1-6,1921Nov. 2008.

[7] Dattaguru V. Kamat, P. V. Ananda Mohan and K. GopalakrishnaPrabhu, "Active-RC filters using two-stage OTAs with and without feed-forward compensation," IET Circuits, Devices and Systems, vol. 5, no. 6, pp. 527-535, Nov 2011. theory. 
[8] Dattaguru V. Kamath, "New OTA-C Current-Mode Second-Order Filters," IIE International Conference on Innovative Engineering Technologies (ICIET 2014) held at Bangkok, Thailand, pp. 137143, 28-29 Dec. 2014.

[9] B.M. Al-Hashimi, F. Dudek, M. Moniri, and J. Living, "Integrated universal biquad based on triple-output OTAs and using digitally programmable zeros," IEE Proc.Circuits Devices Syst., vol. 145, pp. 192-196, 1998.

[10] Dattaguru V. Kamath, "TO-OTA based current-mode biquad filters," Transactions on Engineering and Sciences, vol. 2, no. 8, pp. 15-26, August 2014.

[11] Y. Sun, "Design of current-mode multiple output OTA and capacitor filters,'”International Journal of Electronics, vol. 81, no. 1, 1996.

[12] Dattaguru V. Kamat, P. V. Ananda Mohan and K. GopalakrishnaPrabhu, "Novel first order and second order currentmode filters using multiple output operational transconsuctance amplifiers," Circuits, Systems, and Signal Processing (CSSP), Birkhäuser Boston Publishers, vol. 29, no. 3, pp. 553-576, June 2010.

[13] Dattaguru V. Kamat, P. V. Ananda Mohan and K. GopalakrishnaPrabhu, "Current-mode operational transconductance amplifier-capacitor biquad filter structures based on Tarmy-Ghausi Active-RC filter and second-order digital all-pass filters," IET Circuits, Devices and Systems, vol. 4, no. 4, pp. 346-364, July 2010.

[14] Dattaguru V. Kamath, "Novel OTA-C Current-Mode Third-Order Band-Pass Filters," International Journal of Innovative Research in Electrical, Electronics, Instrumentation and Control Engineering (IJIREEICE), vol. 2, no. 8, pp. 1861 - 1865, August 2014.

[15] TomášDostal, "Filters with multi-loop feedback structure in current mode," Radioengineering, vol. 12, no. 3, pp. 6-11, 2003.

[16] TomášDostál, Milan Sigmund, "Universal third-order state-variable based filter in current mode" Proceedings of the 13th International Czech-Slovak Scientific Conference Radioelektronika, pp. 328-331, 2003.

[17] DraženJurišiü, Neven Mijat and George S. Moschytz, "Design of Fourth-Order Band-Pass Active-RC Filters Using a "Lossy" Lowpass to Band-pass Transformation," European Conference on Circuit Theory and Design (ECCTD’01) held at Espoo, Finland, pp. 117-120, 28-31 Aug. 2001.

[18] DraženJurišić, George S. Moschytz and Neven Mijat, "Lowsensitivity, low-power fourth-order band-pass active-RC all-pole filter using impedance tapering" The 8th IEEE International Conference on Electronics, Circuits and Systems (ICECS 2001), IEEExplorer, vol. 2, pp. 815-818, Sept 2001

[19] Nino Stojkovi'c, Ervin Kamenar, MladenŠverko, “Optimized Second- and Fourth- Order LP and BP Filters," AUTOMATIKA, vol. 52, no. 2, pp. 158-168, 2011.

\section{BIOGRAPHY}

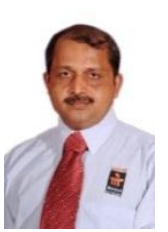

Dr. D. V. Kamath obtained $\mathrm{PhD}$ in the field of Analog VLSI Signal Processing from Manipal University, Manipal,India in the year 2013. He obtained B.E (Electronics and Communication) and M.E (Digital electronics) from B. V. Bhoomreddi College of Engineering and Technology, Karnataka University, Dharwad in the year 1987 and 1997 respectively. Currently working as Professor in the Department of Electronics and Communication Engineering, Manipal Institute of Technology, Manipal, University, Manipal, India. The research and academic contribution includes one US patent, 10 full regular papers published in indexed international journals of good repute, 5 indexed international conference publications. Author's areas of research interest include Digital, Analog and Mixed Signal VLSI design and Analog VLSI Signal Processing. He has presented/ conducted key-note address/ tutorials and seminars at various International/ National Level Conferences/ Workshops. Author's Biography/ Profile is published in the 2011-2012 (11th) Edition of Marquis Who's Who in Science and Engineering and 2014 (31st) and $2015\left(32^{\text {nd }}\right)$ Edition of Marquis Who's Who in the World, the world-renowned reference directories. 